\title{
ИССЛЕДОВАНИЕ ВЛИЯНИЯ СНЕГОСВАЛКИ НА ПОЧВЕННЫЙ ПОКРОВ ПРИЛЕГАЮЩЕЙ ТЕРРИТОРИИ (НА ПРИМЕРЕ ГОРОДА ВОРОНЕЖА)
}

\author{
Т. И. Прожорина, О. В. Крутова \\ Воронежский государственный университет, Россия \\ Поступила в редакцию 18 марта 2019 года
}

\begin{abstract}
Аннотация: Снег, убираемый с городских дорог, несет серьезную экологическую угрозу, связанную с загрязнением почв, поверхностных и подземных вод. В работе дана оценка влияния снегосвалки на почвенный покров прилегающей территории (на примере города Воронежа) на основании результатов химического состава талых вод и почвенных образцов. Автором даны рекомендации по решению проблем, связанных со снегоудалением в городе Воронеже.
\end{abstract}

Ключевые слова: снегосвалка, песко-соляная смесь, кислотность и засоленность почв, противогололедные реагенты, фоновые значения, смешанная проба, снегоудаление.

A study of the influence of the snow dump on the soil cover of the adjacent territory

(Voronezh city is an example)

\section{T. I. Prozhorina, O. V. Krutova}

\begin{abstract}
Snow removed from urban roads poses a serious environmental threat associated with the pollution of soil, surface and groundwater. The article assesses the influence the dump of snow on the soil cover of the adjacent territory (using the example of the city of Voronezh) on the basis of the results of the chemical composition of melt water and soil samples. The authors made recommendations for solving problems associated with snow removal in the city of Voronezh.
\end{abstract}

Key words: snow dump, sand-salt mixture, soil acidity and salinity, anti-icing agents, background values, mixed sample, snow removal.

В городской среде, где наблюдается большое количество как стационарных, так и передвижных источников загрязнения, снежный покров адсорбирует большое количество вредных веществ. В нем обнаруживаются загрязнения, содержащиеся в выхлопных газах автотранспорта и выбросах промышленных предприятий, и даже различные виды отходов [7]. Кроме того, значительный вклад в загрязнение снежного покрова вносят и применяемые антигололедные реагенты различной природы.

В снежном покрове дорог содержится огромное количество опасных для всего живого органических и неорганических химических соединений, различного рода опасных биологических загрязнителей. Именно поэтому особую опасность пред-

(С Прожорина Т.И., Крутова О.В., 2019 ставляет таяние загрязненного снега. Талая вода способна унести вредные вещества на тысячи километров. При таянии снега токсиканты попадают в объекты окружающей среды, главном образом в воду, фильтруясь в почву.

Во многих городах процесс уборки и очистки снега не достаточно оптимизирован, зачастую снежные массы сбрасывают в близлежащие водоемы или на прилегающие к городу необорудованные территории без какой бы то ни было очистки. Все это приводит к неблагоприятным экологическим последствиям: увеличению антропогенного воздействия на водоемы, загрязнению водоносных горизонтов, засолению почв, угнетению роста растительности. Особенно актуальна эта проблема для мегаполисов [4].

Для российских городов этот вопрос недостаточно разработан. В связи с чем авторы статьи по- 
Анализ химического состава снега со снегосвалки

\begin{tabular}{|l|c|c|c|}
\hline \multicolumn{1}{|c|}{ Показатели } & Снегосвалка & $\begin{array}{c}\text { Фон } \\
(500 \text { м от } \\
\text { свалки })\end{array}$ & $\begin{array}{c}\text { Коэффициент } \\
\text { концентрации } \\
\mathrm{C}_{\text {факт }} / \text { Фон }\end{array}$ \\
\hline $\mathrm{pH}$ & 6,9 & 6,75 & - \\
\hline взвешенные вещества, мг/л & 517,24 & 17,1 & $\mathbf{3 0 , 2}$ \\
\hline общ. жесткость, мг-экв/л & 0,47 & 0,1 & $\mathbf{4 , 7}$ \\
\hline $\mathrm{Ca}^{2+}, \mathrm{Mг} / л$ & 7,3 & 1,36 & $\mathbf{5 , 4}$ \\
\hline $\mathrm{Mg}^{2+}, \mathrm{Mг} / л$ & 0,66 & 0,13 & $\mathbf{5 , 1}$ \\
\hline $\mathrm{HCO}_{3}{ }^{-}, \mathrm{мг} / л$ & 29,1 & 7,49 & $\mathbf{3 , 9}$ \\
\hline $\mathrm{SO}_{4}{ }^{2-}, \mathrm{мг} / л$ & 82,1 & 36,1 & $\mathbf{2 , 3}$ \\
\hline $\mathrm{CI}^{-}$мг/л & 103,2 & 3,06 & $\mathbf{3 3 , 7}$ \\
\hline минерализация, мг/л & 221,9 & 51,5 & $\mathbf{4 , 3}$ \\
\hline
\end{tabular}

пытались рассмотреть возможность решения сложившейся ситуации на примере города Воронежа как крупного центра с развитой промышленностью и автотранспортным комплексом.

Существуют различные способы и оборудование для эффективного снегоудаления на городских автомагистралях, тротуарах, внутриквартальных проездах и придомовых территориях. Например, снегосплавные пункты на коллекторах ливневой и хозяйственно-фекальной канализации, сточных водах промышленных предприятий. Другим наиболее экологически безопасными простым способом удаления загрязненных снежных масс являются так называемые «сухие» снегосвалки, которые должны быть оборудованы сооружениями для сбора и очистки талой воды [3].

Однако, несмотря на значительное количество конструкторских разработок и методик, проблема удаления снега в крупных городах далека от разрешения, что, в основном, обусловлено экономическими причинами.

Кроме того, в снеге, убираемом с городских территорий накапливается большое количество биологически трудноокисляемых органических соединений и минеральных веществ. Поэтому после сбора и утилизации снега, необходимо подвергнуть талые воды эффективной очистке [9].

Еще одной особенностью зимней уборки городских территорий является отсутствие мест для складирования снега и его загрязненность антигололедными реагентами и выбросами автотранспорта.

В городе Воронеже уборка снега с проезжей части улиц производится в соответствии с требованиями инструкций, утвержденных жилищнокоммунальным хозяйством [2].

Первые снегоприемные пункты появились в городе Воронеже только в 2000 году. До этого снег с улиц и дворов города выгружался прямо в Воронежское водохранилище. Вместе со снегом в воду попадало большое количество песка, мусора и химических реагентов. Поэтому в 2000 году воронежские власти приняли важное решение о создании специальных снегоприемных пунктов.

Вплоть до 2014 года работало 6 снегоприемных пунктов (снегосвалок), закрепленных за каждым административным районом города.

С 2015 года администрацией города определено, что единственным местом складирования листвы и снега, вывозимого с городской территории является выработанная часть карьера, расположенного в районе пос. Придонской [6]. Примерная площадь снегосвалки составляет 2000 м². Однако, защитное покрытие почвы отсутствует и очистных сооружений для талых вод не предусмотрено, стоки фильтруются в приповерхностные водоносные горизонты.

Несмотря на то, что Управление Роспотребнадзора по Воронежской области ведет мониторинг экологического состояния почв, но такого объекта как городскаяснегосвалка, в программе мониторинга нет.

Мы решили провести исследование влияния снегосвалки на почвенный покров прилегающей территории на основании результатов химического состава талых вод и анализа почвенных образцов, отобранных непосредственно на объекте.

Зимой 2018 года авторами были извлечены смешанные пробы снега с различной глубины (из 8 точек) общим объемом 2 л и образцы почвы после схода снега, т.е. в летний период, непосредственно на месте бывшего снегосклада (из 8 точек) общей массой около 1 кг.

В качестве фонового участка обычно берутся территории, испытывающие минимальное антро- 


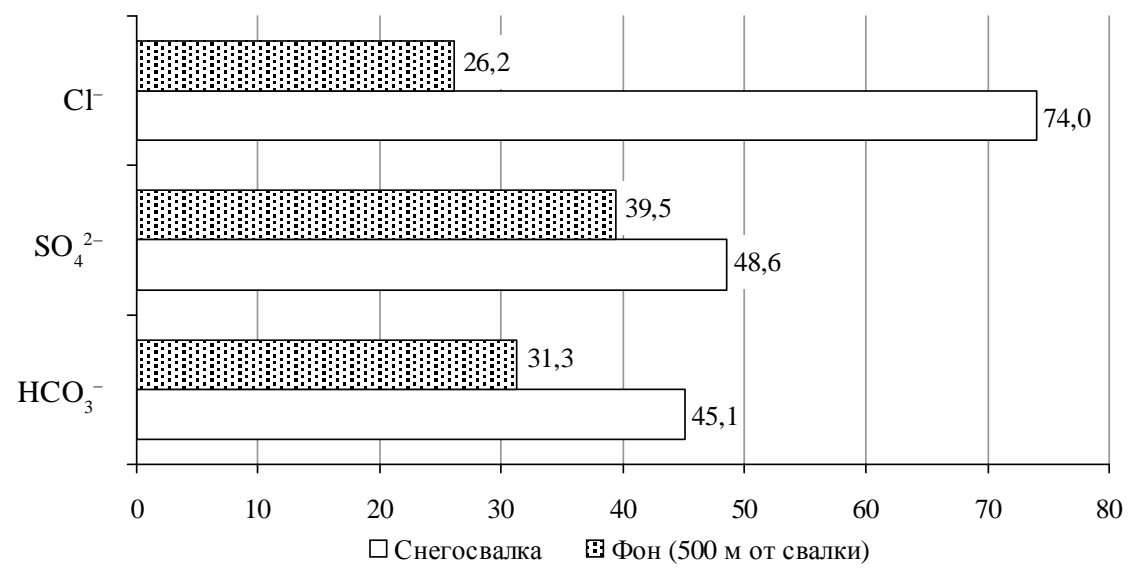

Рис. Сравнительный анализ солевого состава почвенных образцов

погенное воздействие. В данном случае была выбрана «условно-чистая» территория, расположенная в 500 м от снегосвалки - территория лесопосадок.

Пробы снега растапливали при комнатной температуре и анализировали на следующий день. По осадку, полученному на фильтре, определяли количество взвешенных частиц в снеге, а в фильтрате определяли основные компоненты химического состава [1].

Исследования проводились на базе аттестованной эколого-аналитической лаборатории факультета географии, геоэкологии и туризма Воронежского госуниверситета. Химический анализ проб снега и почвы со снегосвалки выполняли с применением следующих методов анализа: весовой (взвешенные вещества); кондуктометрический (минерализация); потенциометрический (pH); титриметрический (общая жесткость, $\mathrm{Ca}^{2+}, \mathrm{HCO}_{3}{ }^{-}$, $\left.\mathrm{SO}_{4}^{2-}, \mathrm{Cl}^{-}\right)$и расчетный $\left(\mathrm{Mg}^{2+}\right)[8]$.

Результаты анализа показали, что все определяемые ингредиенты превышают фоновые значения (таблица). Однако, наибольшее превышение отмечается по взвешенным веществам (в 30,2 раза) и по хлоридам (в 33,7 раза). Это объясняется, тем, что в качестве противогололедных материалов в городе Воронеже используют песко-соляную смесь.

Следующим этапом работы были намечены исследования по определению кислотности и засоленности почв под влиянием снегосвалки.

Кислотность почвы - важнейший экологический фактор, определяющий условия жизнедеятельности почвенных организмов и высших растений, а также подвижность тяжелых металлов в почве.

Засоленность почвы обусловлена повышенным содержанием в ней легкорастворимых минеральных солей, что создает неблагоприятные ус- ловия для развития и роста растений. У растений, произрастающих на засоленных почвах, задерживаются набухание семян, цветение, рост и снижается урожайность. Сильнозасоленные почвы непригодны для выращивания сельскохозяйственных культур, так как при высоком содержании солей наступает гибель растений.

В лабораторных условиях почву просеивали через сито с размером ячеек 1 мм, с помощью $\mathrm{pH}$ метра определяли актуальную $\left(\mathrm{pH}_{\mathrm{H}_{2} \mathrm{O}}\right)$ и потенциальную $\left(\mathrm{pH}_{\text {КсІ }}\right)$ кислотность в водной и солевой почвенных вытяжках [5].

Результаты анализа показали, что по сравнению с фоновым участком, как актуальная, так и потенциальная кислотность повысилась, и характеристика почвы изменилась от «нейтральной» до «слабощелочной». Это связано с присутствием большого количества зольных частиц, содержащих соединения гидрокарбонатов магния, кальция, калия, которые повышают рН почвенных вытяжек. А повышенное содержание зольных веществ в снежной массе объясняется наличием песка, входящего в состав песко-соляной смеси при обработке городских магистралей противогололедными реагентами [9].

Для определения засоленности почвенных образцов установили фактическую концентрацию основных анионов (гидрокарбонаты, сульфаты, хлориды) в водной почвенной вытяжке. На рисунке приведены результаты анализа почвенных образцов, отобранных непосредственно под снегосвалкой, по сравнению с фоном.

Результаты анализа показали, что среди анионов солевого состава в почвенном образце, отобранном под снегосвалкой, доминируют хлориды (74,0 мг/л), хотя в фоновом образце они находятся на последнем месте (26,2 мг/л). Кроме того, все 
основные анионы в пробах почвы превышают аналогичные фоновые значения. Однако, наибольшее превышение отмечается по хлоридам (в 2,8 раза). Это объясняется, тем, что в качестве противогололедных материалов в городе Воронеже используют песко-соляную смесь.

В зависимости от концентрации солей, определили тип засоления - «смешанный» с преобладанием хлоридов, степень - «среднезасоленная».

Таким образом, если продолжать использовать данную территорию под снегосвалку при отсутствии необходимых сооружений для сбора и очистки талой воды, то через несколько лет почвенный покров перейдет в категорию «хлоридного» засоления, а после весеннего снеготаяния засоленные талые воды могут нанести непоправимый вред окружающей среде, связанный с загрязнением почв, поверхностных и подземных вод.

В индустриальном городе как Воронеж для решения вопросов, связанных с удалением снега, необходим комплексный подход.

1. Сброс снега непосредственно в канализационные каналы, без учета его качественного состава, приводит к засорению сооружений сети и, в результате, к трудоемким и дорогостоящим работам по очистке коллекторов. Снежные массы, вывозимые с городских территорий сильно загрязнены песком, нефтепродуктами, антигололедными реагентами, уличным мусором. Талая вода от убираемого снега не соответствует не только нормативам по сбросу в водоемы, но зачастую и нормам приема стоков в городскую канализацию.

Таким образом, несмотря на то, что «сухие» снегосвалки являются наиболее простым методом удаления снега с городской территории, они должны быть оборудованы сооружениями для сбора и очистки талой воды.

2. В городе Воронеже имеется дефицит больших площадей городских земель под устройство «сухих» снегосвалок. Например, по нормативам для размещения 1 млн. м ${ }^{3}$ снега, площадь такой свалки должна быть не менее 12 га. Для размещения 213478 м $^{3}$ снега, примерно вывозимого с улиц города Воронежа за год, площадь снегосвалки должна быть не менее 2,4 га. В тоже время площадь городской снегосвалки (по данным 2015 года) составляет всего 0,2 га, что в 12 раз меньше нормы. Эти расчеты подтверждают острую необходимость внедрения стационарных или мобильных снегоплавильных установок в городе.

3. Так как загрязненный снег, вывозимый с городских территорий, представляет серьезную эко- логическую угрозу, связанную с загрязнением почвенного покрова, поверхностных и подземных вод, необходимо осуществлять постоянный контроль и мониторинг за влиянием эксплуатации снегосвалки на состояние окружающей среды. В связи с тем, что в настоящее время в городе Воронеже «сухие» снегосвалки не оборудованы надлежащим образом, а снегоплавильные установки отсутствуют, в программу мониторинга экологического состояния почв, осуществляемого Управлением Роспотребнадзора по Воронежской области, должен быть включен такой параграф как «городская снегосвалка».

Исследование проведено при финансовой поддержке Русского географического общества, проект РГО-РФФИ № 17-05-41072.

\section{СПИСОК ЛИТЕРАТУРЫ}

1. Аэротехногенный мониторинг состояния городской среды по загрязнению снежного покрова (на примере города Воронежа) / Т. И. Прожорина [и др.] // Вестник Волгоградского государственного университета. Сер. 11, Естественные науки. - 2014. - № 3(9). C. 28-34.

2. Генеральная схема очистки территории городского округа город Воронеж. - Воронеж, 2013. - 186 с.

3. Корецкий В. Е. Экологичное снегосплавление / В. Е. Корецкий // Коммунальный комплекс России. Сер. Дорожное хозяйство. - Москва : МосводоканалНИИпроект, 2006. - № 2. - С. 20-24.

4. Очков В. Ф. Снег в мегаполисе и энергетика / В. Ф. Очков // Энергосбережение и водоподготовка. 2005. - № 1. - С. 86-92.

5. Орлов Д. С. Химия почв : учебник / Д. С. Орлов, Л. К. Садовникова, Н. И. Суханова. - Москва : Высшая школа, 2005. - 557 с.

6. Правила Благоустройства территорий городского округа город Воронеж ПРАВИЛА (в ред. решений Воронежской городской Думы от 08.07.2009 N 203-II, от 03.03.2010 N 33-II,от 20.02.2013 N 1077-III, с изм., внесенными решением Арбитражного суда Воронежской области от 16.10.2009 по делу N A14-11562/2009/ 273/24).

7. Прожорина Т. И. Снежный покров как индикатор загрязнения атмосферы / Т. И. Прожорина, Н. А. Шилкина // Экологические проблемы промышленных городов : сборник материалов IV всероссийской научно-практической конференции с международным участием. - Саратов, 2009. - Ч. 1. - С. 188-191.

8. Эколого-аналитические методы исследования окружающей среды : учебное пособие / Т. И. Прожорина [и др.]. - Воронеж : Истоки, 2010. - 304 с.

9. Эколого-геохимическая диагностика состояния городской среды по загрязнению снежного покрова г. Воронежа / Т. И. Прожорина [и др.] // Проблемы природопользования и экологическая ситуация в Европей- 
ской России и сопредельных странах : сборник материалов V международной конференции. - Москва; Белгород, 2013. - С. 131-134.

\section{REFERENCES}

1. Aerotekhnogennyy monitoring sostoyaniya gorodskoy sredy po zagryazneniyu snezhnogo pokrova (na primere goroda Voronezha) / T. I. Prozhorina [i dr.] // Vestnik Volgogradskogo gosudarstvennogo universiteta. Ser. 11, Estestvennye nauki. - 2014. - № 3(9). - S. 28-34.

2. General'naya skhema ochistki territorii gorodskogo okruga gorod Voronezh. - Voronezh, 2013. - 186 s.

3. Koretskiy V. E. Ekologichnoe snegosplavlenie / V. E. Koretskiy// Kommunal'nyy kompleks Rossii. Ser. Dorozhnoe khozyaystvo. - Moskva : MosvodokanalNIIproekt, 2006. - № 2. - S. 20-24.

4. Ochkov V. F. Sneg v megapolise i energetika / V. F. Ochkov // Energosberezhenie i vodopodgotovka. 2005. - № 1. - S. 86-92.

5. Orlov D. S. Khimiya pochv : uchebnik/D. S. Orlov, L. K. Sadovnikova, N. I. Sukhanova. - Moskva : Vysshaya shkola, 2005. - $557 \mathrm{~s}$.

\section{Прожорина Татьяна Ивановна}

кандидат химических наук, доцент кафедры геоэкологии и мониторинга окружающей среды факультета географии, геоэкологии и туризма Воронежского государственного университета, г. Воронеж, т. (473)266-56-54, E-mail: coriandre@ rambler.ru

Крутова Ольга Владимировна

кандидат географических наук, доцент кафедры рекреационной географии, страноведения и туризма факультета географии, геоэкологии и туризма Воронежского государственного университета, г. Воронеж, т. (473)266-56-54, E-mail: prokhorova.vsu@mail.ru
6. Pravila Blagoustroystva territoriy gorodskogo okruga gorod Voronezh PRAVILA (v red. resheniy Voronezhskoy gorodskoy Dumy ot 08.07.2009 N 203-II, ot 03.03.2010 N 33-II, ot 20.02.2013 N 1077-III, s izm., vnesennymi resheniem Arbitrazhnogo suda Voronezhskoy oblasti ot 16.10.2009 po delu N A14-11562/2009/273/24).

7. Prozhorina T. I. Snezhnyy pokrov kak indikator zagryazneniya atmosfery / T. I. Prozhorina, N. A. Shilkina // Ekologicheskie problemy promyshlennykh gorodov : sbornik materialov IV vserossiyskoy nauchno-prakticheskoy konferentsii s mezhdunarodnym uchastiem. - Saratov, 2009. - Ch. 1. - S. 188-191.

8. Ekologo-analiticheskie metody issledovaniya okruzhayushchey sredy : uchebnoe posobie / T. I. Prozhorina [i dr.]. - Voronezh : Istoki, 2010. - 304 s.

9. Ekologo-geokhimicheskaya diagnostika sostoyaniya gorodskoy sredy po zagryazneniyu snezhnogo pokrova g. Voronezha / T. I. Prozhorina [i dr.] // Problemy prirodopol'zovaniya i ekologicheskaya situatsiya v Evropeyskoy Rossii i sopredel'nykh stranakh : sbornik materialov V mezhdunarodnoy konferentsii. - Moskva; Belgorod, 2013. - S. 131-134.

Prozhorina Tatiana Ivanovna

Candidate of Chemical Sciences, Associate professor of the Department of geoecology and environmental monitoring of the Geography, Geoecology and Tourism Faculty of the Voronezh State University, Voronezh, tel. (473)266-56-54, E-mail: coriandre@ rambler.ru

Krutova Olga Vladimirovna

Candidate of Geographical Sciences, Associate professor of the Department of recreational geography, regional studies and tourism of the Geography, Geoecology and Tourism Faculty of the Voronezh State University, Voronezh, tel. (473)266-56-54, E-mail: prokhorova.vsu@ mail.ru 